\title{
Teaching student teachers: various components of a complex task
}

\author{
Hans Humenberger and Hans-Christian Reichel
}

\begin{abstract}
In this paper we summarize various aspects of teacher training and teaching student teachers (mainly concerning teachers of upper secondary school and High school). We stress several hints and recommendations to better achieve the obviously important aim: they should learn doing, understanding and teaching mathematics!

Of course, our view is particularly influenced by European traditions, but we think most of them equally apply to teacher training and teaching student teachers elsewhere. Neither is the paper meant to give an all sided overview about the problem field of teacher education as a whole, nor does it contain provocative, completely new ideas. We just want to describe our view of some aspects, based primarily on our personal experience in the mentioned field.
\end{abstract}

Key words and phrases: teacher education, teacher training.

ZDM Subject Classification: B50.

\section{Introduction}

There has been a growing international discussion since the middle of the seventies about special qualifications of mathematics teachers and about what kind of training would be appropriate to develop them. Considerable research on mathematics education has been done so far (theoretical and empirical work with all its sub-aspects) with at least two different aims:

Prof. Reichel died in June 2002 and this is the last paper published by him. The first author wants to thank Prof. Reichel for all his efforts concerning himself and the whole realm of teacher education in general.

Copyright (C) 2003 by University of Debrecen 
1. To identify those skills and abilities which really will improve the later (and professional) work of our student teachers in classroom. I.e.: which abilities characterize "good" teaching of mathematics and how could those be trained at university?

2. Mathematics education and "Didactics of Mathematics" should become an independent and broadly accepted part of science. Courses for student teachers should not be sort of an appendix in a general mathematics study program; we need special study programs for mathematics teachers. Understanding the processes taking place when mathematics is taught in classroom includes many aspects of various fields. All that has to be a scientific object for research and an important item in teaching student teachers: Problems of mathematics education have to be integrated in study programs for teachers.

Similar ideas have been expressed by E. C. Wittmann $(1995,356)$ where he writes that

"the specific tasks of mathematics education can only be actualized if research and development have specific linkages with practice and their core and if the improvement of practice is merged with the progress of the field as a whole."

Following this paper of Wittmann the main tasks of research in mathematics education for the future can be described like this: analysis of mathematical activity and of mathematical ways of thinking, development of local mathematics education theories (e.g. on "mathematizing", problem solving, proofs themselves, and practicing skills), exploration of possible contents that focus on making them accessible to learners, critical examination and justification of contents in view of the general goals of mathematics teaching, research into the prerequisites of learning and into the teaching/learning processes, development and evaluation of substantial teaching units, classes of teaching units and curricula, development of methods for planning, teaching, observing and analyzing lessons, inclusion of the history of mathematics education.

Moreover, we would like to add several items as: ways (modes, procedures, aims) of examinations, research concerning typical students' mistakes, finding (new) ways to genuinely integrate applications of elementary mathematics into mathematics courses for student teachers at university and for students at all school levels (applicable - not applied - mathematics, "how to teach mathematics so as to be useful?" in the spirit of H. Freudenthal; see also Humenberger/Reichel 1995). 
Although our main efforts must be to improve the educational practice ${ }^{1}$, we think that without any theories concerning learning and teaching the students' difficulties in learning and understanding special pieces of mathematics are poorly noticed or even remain undiscovered. To understand the difficulties and to be able to counteract in some ways, is obviously a practical aim in mathematics education. These theories should not only guide the teacher educators implicitly but they should be explicit parts of some courses ${ }^{2}$ (lectures, seminars). Student teachers should actively reflect on theories for practical reasons: to be able to notice the difficulties of learning processes of pupils in their later classroom practice.

We all know that a great number of mathematicians still believe that - for a gifted and well trained mathematician - there is nothing behind teaching mathematics in classroom and that doing research in mathematics education is just doing easy mathematics and second class research. However, besides this obviously wrong view, there are also critical comments by mathematics education researchers. N. Balacheff et al. $(1993,14)$ for instance write:

"Despite this lack of consensus [what the meaning of research in mathematics education is], publications appear that endeavour to depict the 'state of the art' in mathematics education research. Individuals try to construct didactical theories. But reviewers never have trouble demonstrating the one-sidedness of such publications. Attempts to describe research in mathematics education or didactique des mathematiques or whatever other name is used many resemble the accounts of the legendary blind men exploring the legs of a huge elephant."

\section{Education of mathematics teachers}

It would be easy to optimize teacher education at university and classroom teaching at school if we knew exactly which factors are responsible for "really" understanding mathematics and what that means after all. But we surely won't

\footnotetext{
${ }^{1}$ We always should keep in mind: handling problems and preparing lessons (not discussing or communicating theories or views) will constitute the greater part of the professional life of student teachers later on.

${ }^{2}$ We do not go into detail concerning the important concrete spheres of psychology (developmental and cognitive), general pedagogy, or epistemology; this would be a topic for another paper (by other authors).
} 
find a generally valid model that describes classroom practice or teacher education as a function of some "teacher-variables" such as mathematical knowledge, educational knowledge, philosophical views and attitudes towards mathematics, abilities in problem solving and in motivating and guiding the students' learning processes. There is a very complex relationship between the teachers' conceptions of mathematics and their classroom practice as several studies show (cf. e.g. Cooney 1985).

\subsection{Desired qualifications of mathematics teachers}

It is well accepted that there should be two constituent parts in teacher education:

(i) knowledge of mathematics (especially elementary mathematics)

(ii) educational and didactical knowledge.

It is obvious that mathematical knowledge is the indispensable basis for the work of every mathematics teacher. One hardly can imagine serious plans for mathematics teacher study programs without courses in mathematics. On the other hand, for some mathematicians at university who give lectures to preservice teachers it is still not really obvious that mathematics student teachers also need to think about and learn educational and didactical aspects.

Already about thirty years ago T. J. Fletcher stated the demand for these two components by writing $(1975,217)$ :

"The teacher of mathematics certainly needs to be a mathematician, and he needs to be a special sort of mathematician. He needs the general mathematical background that enables him to talk on equal terms with mathematics graduates [...]. He needs a broad knowledge of applications in the world outside and in other parts of the school curriculum.

In addition the teacher needs specialist skills of his own, in the translation of mathematics from one form into another, in understanding the pattern of thinking of his pupils at various stages of development and in understanding the relevance of structural ideas in mathematics to the teaching of it."

Although the words "education" or "didactics" are not used here, this text clearly says that both is important for a mathematics teacher: mathematical knowledge and understanding of learning processes. But there is no real consensus about the balance of them. In Austria (and also in Germany and many other European 
countries) there is a great difference between educating primary and secondary school teachers: the main goal in educating primary school teachers is to be seen in educational and didactical courses, whereas the education of secondary school teachers - quite on the contrary - strongly focuses to purely mathematical matters. In both cases, the corresponding other part of training is not completely neglected but plays a comparatively small role.

We definitely should not just add a few "didactical courses" to the "mathematical" ones if we suspect some defects of the study program. Separating those aspects will cause further defects and misunderstandings. A carefully planned balance and integration of mathematical and educational aspects as constituent and coordinated parts of study programs ${ }^{3}$ will not only improve teacher education, it probably will also show possibilities to get free space and time to augment the teacher training programs at university.

There is an obvious difference between doing mathematics or solving problems and teaching or encouraging someone to do so. Therefore, student teachers - in addition to teaching abilities - need special qualities, attitudes, and views amalgamated with the mathematical subjects they have to learn in, say, "classical" mathematics courses. Although an old problem, it is a fairly open question to identify, classify and investigate such abilities, qualities, attitudes, and views in a scientific way.

First of all, we teacher educators should develop and stress a catalogue of such relevant qualities which mathematics courses for student teachers should aim at.

Whenever discussing schedules and curricula, there are people who complain about the often small portion of courses on mathematics education, but others claim that student teachers would show severe lacks of mathematical knowledge and that this would be the reason of all further problems at school. Obviously, also the educational requirements presuppose good knowledge of mathematics.

Besides these desired qualifications (mathematical knowledge, mathematics education) another quality which should especially be stirred by courses to mathematics student teachers is fondness of and well measured enthusiasm about mathematics, which clearly are attitudes teachers should have if teaching mathematics is not to be reduced to just a technical process or to teaching formal or social qualities only. We think lectures introducing students to mathematics and mathematics to students are the most important ones for shaping the students' attitudes

${ }^{3}$ This integration and balance is meant to be realized within the whole study program (balance between courses that primarily deal with one aspect) as well as within many courses themselves (courses that are concerned to both aspects) - see also the next section. 
towards mathematics and their ability to transmit fascination, motivation, and interest for the subject. This is probably a much more difficult task than explaining the subjects involved (mathematical facts) properly; but both abilities are necessary for teaching a subject successfully.

\subsection{Mathematical and educational aspects of study programs}

In most countries of the world, students aiming to become mathematics teachers in secondary school have to attend university courses. In most cases, the curricula are twofold:

- courses which include "classical subjects" of mathematics (lectured in most cases by mathematicians - mainly in the first part of the students' studyperiod) and

- courses devoted to special knowledge concerning teaching in the classroom and its professional aspects, i.e. educational and didactical knowledge (given by teacher educators - mainly in the second part of the students' study period).

But in spite of this apparent separation of goals, we do not think that acquisition of teaching abilities, attitudes, and knowledge should be reserved for or postponed to the second kind of courses only. We ought to establish a genuine integration of both when developing courses for students, mathematical and didactical (also educational) knowledge. The educational and didactical knowledge of mathematics teachers can hardly be acquired in separation from mathematics. T. J. Fletcher has a similar point of view, too. He writes $(1983,113)$ :

"The intending teacher needs the opportunity to learn (at his own level) by methods which he could later adopt in his teaching. Whatever mathematical content is involved the student should meet the ideas in forms which respect his previous knowledge and his methods of thinking as far as they have evolved. [...] When we are teaching mathematics to student secondary teachers, teaching method is not a subject apart. In many training institutions these two components are treated separately, but good mathematics and good methods can be studied simultaneously to the benefit of both. Let us make this our major fundamental change."

E. C. Wittmann (1989), too, deals with the question of combining educational and mathematical requirements in teacher education programs. He shows a way 
how teacher perspectives and didactical aspects could be integrated into courses of elementary mathematics and describes an approach to integrating the mathematical and educational components in teacher training. This approach is based on elaborating educational and psychological aspects that are inherent in "good mathematics". With this in view, Wittmann $(1989,299)$ asks for courses in elementary mathematics which should

1. be explicitly related to the content of school mathematics,

2. be rich in relationships to history, culture and the real world, and should involve applications to mathematical phenomena in the environment of pupils,

3. be organized in a genetic way, i.e. problem- and process-oriented with heuristics included in a prominent manner,

4. be informal or pre-formal,

5. allow for a variety of teaching/learning formats,

6. deal implicitly or even explicitly with the teaching of school mathematics.

These demands are related to our paper, too. All of Wittmann's comments (see also Wittmann 2001) concerning mathematics education of primary school teachers apply mutatis mutandis as well to mathematics education of teachers of other levels. But to transform his suggestions and ideas to the secondary school and High school mathematics teacher training is a rather complex task and needs a lot of research experiments - we are at the beginning of this process yet.

It is clear that the education of upper secondary and high school mathematics student teachers cannot be reduced to school mathematics and elementary mathematics only, also "higher mathematics" (mostly presented in a formal way) has to be in their study program to some extent, but not exclusively; we think elementary mathematics has to be forced in most study programs of student teachers (primary school, secondary school and also High school student teachers) since it plays a too small role in most cases.

Especially the education of upper secondary and High school mathematics teachers is sometimes too formal, too "high"; elementary mathematics (with concrete phenomena and concrete underlying imaginations) is often not as important as it should be. There is something wrong when teacher students take part in a seminar about orthogonal functions but do not know that $\sin \left(180^{\circ}-\alpha\right)=\sin \alpha$, and even less why. Another example on geometry: 16 out of 18 upper secondary student teachers at the end of their study program did not know the elementary theorem about the angles at a circumference of a circle; we think that this is 
alarming in some sense, even if they could handle exercises on, say, using the principal axis theorem.

Of course, for student teachers, it is of special importance to realize the mutual actions and effects between the concrete mathematical substance and the way it is viewed and taught. Being aware of them and being able to freely choose or independently alter these ways of teaching (concerning any concrete subject or level in question) makes the superior teacher. Moreover, it strongly correlates with the ability of assessing appropriately mathematical subjects in school curricula. These very important and desired achievements should not be postponed to one or another special course in a second phase of the study program, they should be explicit aims of all courses from the very beginning till the end of the study program. Unfortunately and contrary to this requirement, university teachers themselves often follow only one narrow way of teaching, and this may influence the student teacher (and later inservice teacher) more than any lecture devoted to teaching activities later on.

\section{Philosophy of teaching, shaping students' views}

\subsection{Philosophy of teaching}

Our philosophy of educating student teachers may shortly be described like this: Teachers should be competent and professional decision makers and not only persons who implement mathematical ideas into the "mathematically empty field" of students. Proper teaching cannot mean to load the students' brains with as many mathematical issues as possible (like filling a pot) without active participation of the students. They should have the broad opportunity and duty ${ }^{4}$ to get experiences in doing "personal researches" and in constructing mathematics. These skills definitely will help the student teachers to improve their performance in the classroom later. T. J. Cooney $(1988,355)$ writes:

"A humanistic orientation emphasizes the teacher as a decision maker who determines what mathematics students are capable of learning and what strategies are appropriate given the mathematical maturity of students.

\footnotetext{
${ }^{4}$ Nowadays it seems to be a widely spread phenomenon that students just want to "consume" education passively (just like a film in TV). But if they are not ready to take part with a great deal of activity every education will probably fail.
} 
Can you imagine any greater task for teacher education than educating teachers to make such decisions?"

Of course, teachers can only provide the chance for understanding; this does not necessarily cause understanding itself; to take this chance actively is the necessary part of the students. It is evident that motivating is a main job of teachers. However, nowadays it seems to be usual that teachers also have to explain why they teach special themes. Some others even ask for students' participation in choosing the material. Here we want to warn researchers in mathematics education to reduce their work to finding motivations. On the other hand, research in no way should exclusively consist of problem solving or producing several kinds of "mathematical miniatures". Teachers, by their academic training, must combine mathematical knowledge with knowledge about the significance of their themes within science and applications on the one side, and with knowledge about the process of learning on the other (with respect to psychology, pedagogy, sociology and others). Teaching mathematics means much more than transmitting certain themes to a often not interested crowd of pupils. Knowledge can not be taught by teachers merely acting as transmitters, nor can it be learned by students merely acting as passive receivers.

\subsection{Responsibility of teachers and teacher educators: shaping the students' views of mathematics}

Valuing, balancing and assessing mathematical subjects and discussing relations to other (and possibly totally different) fields of mathematics or of other domains are some of those qualities which should be gained by students during their academic training. Whenever teaching any subject (at any level) you also transmit a certain view of the subject, a certain conception, apprehension and interpretation of the subject in question, no matter whether you are aware of it or not.

Every teacher (at school or at university) bears a great responsibility: Teaching mathematics to students over quite a long period considerably influences the students' attitude towards mathematics; even more, for most students, mathematics lessons at school are the only contact with mathematics at all. Thus it seems justified to say that mathematics instruction in school nearly exclusively is responsible for what people think mathematics is, which problems can be solved by mathematical means, why mathematics is important etc. We are deeply convinced that the teachers' views about mathematics are transported to 
their students explicitly or implicitly and that this transport of philosophies has considerable effects to the students' views and philosophies about mathematics. In general, teaching student teachers is a great challenge in the following sense: at university the students' attitudes are influenced by the teacher educator and later the teachers' attitudes influence their pupils' thoughts about mathematics. Mathematics teachers at all levels are "multipliers of mathematical attitudes" and this is a great task in fact.

Therefore, and by further reasons given later, we accentuate the great and specific responsibility of all academic teachers who give mathematics courses to student teachers. We try to formulate explicit suggestions, and most of them are based on our personal experience.

It is quite natural that teachers, later in classroom, copy somehow the way of teaching as they have experienced it at school or university. Thus it is a special challenge and responsibility of those giving courses to student teachers. On the other side, teaching aims, conditions and principles at university are necessarily different from those at secondary schools. Therefore, in our mathematics lectures, in addition to the mathematical cores, we must try to offer also more or less implicit items by which student teachers can benefit.

\section{Improving the desired students' qualifications}

There are many possibilities to specifically adapt mathematics lectures to the needs of prospective mathematics teachers by all of which other mathematics students would benefit, too. One of them is: the internal concept of any course and the way it was developed should be a part of the course itself. Alternatives and genetic aspects should be discussed and balanced within the course; the motives having led to the specific structure of the course should be included into the course and elucidated. Awareness of the genetic aspects inherent as well in the subject as in the teacher's concept of the course will obviously improve teaching qualifications of student teachers.

In the following we shall develop this idea in more details and we shall expose other possibilities of (means for) improving the desired students' qualifications when teaching mathematics teacher students.

In mathematics courses given to student teachers, university teachers should try to be aware of many hidden aspects of the course. The most important of them should be made explicit to the student teachers, so that students sometimes could witness and share some of the decisions the lecturer has to make when preparing 
the course. Realizing the necessity, the kind, and the complexity of such decisions by concrete examples is very important for mathematics student teachers.

Hereto, a parallel regular meeting, say one hour every two weeks or even every week, can be offered to student teachers being pursued by the lecturer himself or by a specifically trained teaching assistant who, of course, should then be present in the (so-called) main lecture, too. Besides reflections on the content of the lecture and its significance, there are further demands on mathematics lectures given to student teachers which possibly could also be fulfilled in such parallel meetings or seminars. To give just one example: a major part of any teacher's professional life is, of course, to prepare courses, i.e. to unfold a subject by creatively combining facts and applications, by choosing suitable introducing frames and - especially important - the teacher succeeds or fails by posing and eventually creating striking and well-aimed problems to elucidate the subject in question. But in most cases the student teacher does not learn anything of that while preparing for the usual kind of examinations, although all these qualifications could efficiently be trained parallel to learning the usual mathematical cores.

Finding or creating problems instead of only solving given ones will certainly support the process of understanding on every level of mathematics. To give just one example, think of conditional probability and the realm of Bayes' formula. The idea of it certainly will be understood adequately rather by formulating problems being solved by these methods, than by just applying them to a bunch of problems as they usually follow the "theory" in "classical" textbooks and teaching frames.

Students should learn to use textbooks autonomously (which clearly is an important skill of student teachers). They should be asked to search (in two or three books) for a proof of a theorem which was only cited in the main lecture, and to report this proof (e.g. during a parallel meeting mentioned above). The students should learn to look up or even find autonomously special "things" in the literature and - which is even more important - to adapt them to the conception and notation of the course, an ability which is obviously desirable for student teachers. At the same time, students will also learn to combine and freely handle different frames and notations of a given subject.

Another means to promote wanted abilities and attitudes is to ask the students to prepare elaborate notes of at least some parts of the course. The quality of these notes should be such that - as an assumption - students who had missed several lectures could use these notes for learning what they have missed. Then, presenting these notes should become a part of the final exams (compare Sec- 
tion 5.2). Preparing elaborate notes of several chapters of a lecture will also help the students to find the threads of thought and fundamental ideas which are characteristic for the course in question, its mathematical subject and the way it is or was taught. In most theories, we can discover more than one continuous thread of thought; most subjects are based on a "network" of leading ideas, from which the teacher has to choose one or two to be stressed in a certain course. University teachers giving courses to student teachers should give hints to recognize these "paths" along which the subject is developed. They also could mention one or two other ways leading "through the network" of the subject in question. Moreover, by preparing elaborate notes, misconceptions and misunderstandings can be discovered at a very early stage.

\section{Preformal reasoning, problem solving, exams}

\subsection{Elementary and applicable mathematics, problem solving}

Mathematics has many "faces" that can (very roughly) be classified in two main-groups:

- Mathematics as a formal, consistent and logically organized system of symbols, axioms, procedures, proofs and the like.

- Mathematics as a (through many centuries improved) method or technique to solve problems: real world problems and others.

It is clear that every kind of mathematics instruction should show both faces but the question is to what extent? In general, nowadays the formal aspect of mathematics is the prominent one in average teaching and therefore it seems justified and necessary to force the practical aspect (i.e. "applicable mathematics"; see especially Humenberger/Reichel 1995). This does not mean that we want mathematics to be taught primarily from the viewpoint of applications, but the role applications play should be increased in our lectures. Although this has been required for years and a lot of material has been published there is no broad success internationally. There is always a sort of misunderstanding, too. We cannot and should not teach applied mathematics at schools, but we should teach mathematics in such a way that the applicable character of mathematics becomes apparent. And this can be done with teaching most parts of mathematics, in particular elementary mathematics. 
Especially in the elementary fields of mathematics, it should become evident in various situations that mathematics can be seen as a language into which problems have to be translated in order to be able to use the formal system "mathematics" to solve them or at least to get special hints on the structure of the posed problems and their possible solutions ("problem solving by proper translation into the language of mathematics"). Students of elementary mathematics ${ }^{5}$ courses should make rich experiences ("process orientation") in how mathematics can help to solve problems, "pure mathematical ones" and especially "real world"problems. Students should learn to see the two faces of mathematics: on the one hand, mathematics as a language, a body of theories: mathematical items and facts (represented by graphs, pictures, definitions, theorems, formulas and other symbols) are "intellectual creations" in a deductively ordered world. On the other hand, mathematics as a means for better describing and solving real world problems.

To summarize this viewpoint: concrete phenomena and structures that can fascinate students and make them think deeply for themselves, but also substantial reasoning (formal and especially pre-formal) should be in the very center of mathematics education! This view is also expressed very shortly and impressively by Gale 1990:

"The main goal of all science is first to observe and then to explain phenomena. In mathematics the explanation is the proof."

Doing mathematics (on arbitrary levels) means to discover this science with all its contrasting faces which occasionally seem to oppose each other:

Complexity versus Simplicity,

Deduction versus Construction,

Logic versus Imagination,

Generality versus Individuality,

Inventing Concepts versus Exactifying Seemingly Established Ones like number, measure, volume and others,

Building Theories versus Solving Problems (e.g. from "every-day-life") and the like.

Prospective teachers should be able to make clear these sometimes contrary positions by many concrete examples (on school level and levels beyond, of course).

${ }^{5}$ Elementary mathematics is here meant to have strong linkages to school mathematics, to concrete problem situations, to interesting and fascinating phenomena and structures, to heuristics, to pre-formal representations etc. 
Therefore, it is necessary that students learn to think, speak and argue on a preformal level, too. To give just two reasons:

1. They ought to do and teach so at school later on by themselves.

2. Short heuristic (and maybe contrasting) reasoning - based on understanding - will probably be better kept in mind by students.

By stressing pre-formal and heuristic activities we do not ask for abolishing mathematical exactness from education; we just say that we should enable the students to give short and reasonable pre-formal answers to as many mathematical questions and situations as possible. We would like to give two short examples concerning the concept of integration.

- "Why can the length $\ell$ of a graph $y=f(x)$ between $a$ and $b$ be calculated by the formula $\ell=\int_{a}^{b} \sqrt{1+\left[f^{\prime}(x)\right]^{2}} \mathrm{~d} x$ ?"

Here we know the way of arguing like physicists (without explicitly using the Mean Value Theorem, but handling the differentials $\mathrm{d} x, \mathrm{~d} y, \mathrm{~d} s$ like numbers):

$$
\mathrm{d} s=\sqrt{(\mathrm{d} x)^{2}+(\mathrm{d} y)^{2}}=\sqrt{1+\frac{(\mathrm{d} y)^{2}}{(\mathrm{~d} x)^{2}}} \mathrm{~d} x=\sqrt{1+\left[f^{\prime}(x)\right]^{2}} \mathrm{~d} x .
$$

Now, to determine the length we have to "sum up" all the small parts $\mathrm{d} s$.

Such reasoning should not be neglected with the words, say, "this reasoning lacks exactness, furthermore it does not say anything about necessary prerequisites" and so on. Of course, a "real" proof looks different but this is appropriate reasoning (in our opinion) if the basic ideas of calculus are well known and well understood. Beside the pre-formal contents of such reasoning another item is worthwhile mentioning: students should be given the chance and the obligation to speak freely about mathematical facts, to argue independently, to formulate sentences of their own. Note that a main part of their later professional live is dedicated to preparing lessons and speaking (explaining) with own words.

Curiously enough, student teachers are trained in many different ways, but later in classroom, their main business will be speaking (about mathematical matters and educational affairs). When and where do student teachers learn to speak freely about given problems and theoretical matters?

- Another example would be to argue for the opposite character of integration and differentiation. Let's assume a textbook shows a picture like Figure 1 


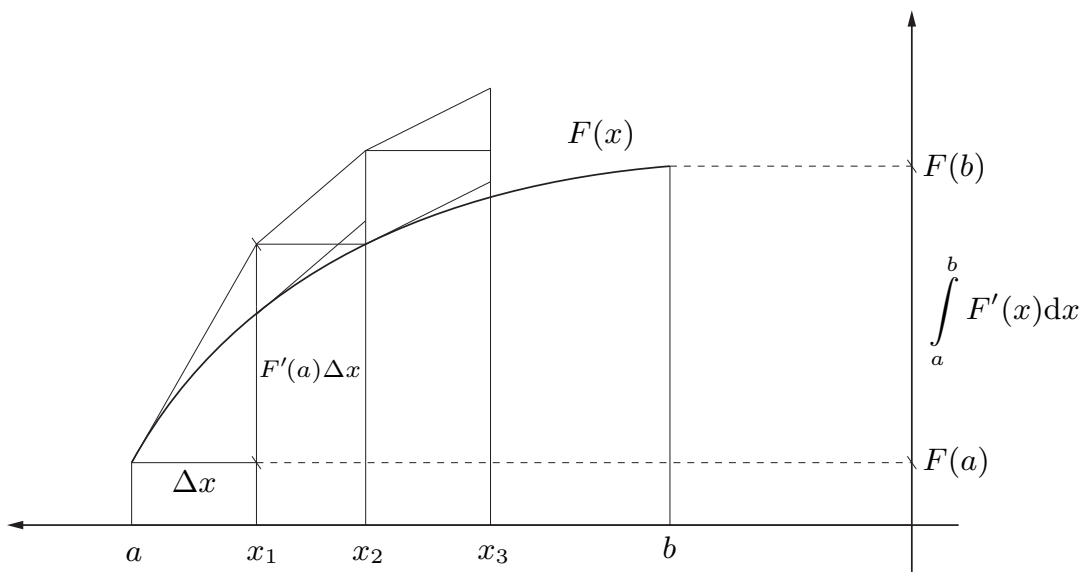

Figure 1. Reconstructing $F$ from $F^{\prime}$

and a text like this:

"Explain by own words in a few minutes the meaning of Figure 1. How can we reconstruct a function $F$ from its derivative $F^{\prime}$ ? What does the following formula tell us? $F(b)-F(a)=\sum\left(F\left(x_{i+1}\right)-F\left(x_{i}\right)\right) \approx \sum F^{\prime}\left(x_{i}\right) \Delta x_{i} \rightarrow$ $\int_{a}^{b} F^{\prime}(x) \mathrm{d} x$. Finally, of course, this yields $F(b)-F(a)=\int_{a}^{b} F^{\prime}(x) \mathrm{d} x$."

Although the facts should be easy for any post-college student, speaking freely (small pre-formal talks) usually leads to astonishing situations in our seminars for students. Therefore, let us stress such items when teaching student teachers!

It should become clear to students what the learned contents could mean in every-day-language and they should be able to express short and appropriate statements concerning the underlying ideas. Preformal arguing and autonomous (but competent) speech are important skills of student- and inservice teachers.

Further examples concerning the elementary realm of integrals (areas below the graph of a function; these examples apply primarily for teaching at school but analogous questions should be dealt with on every level and with respect to arbitrary mathematical contents):

1. In Figure 2a the velocity of two cars is shown as a function of time.

(a) Which car will be ahead one minute after starting if both cars started at the same point? Did they cover the same distance?

(b) Does the distance between the two cars increase or decrease at the time (moment) $t=0.8$ minutes? 


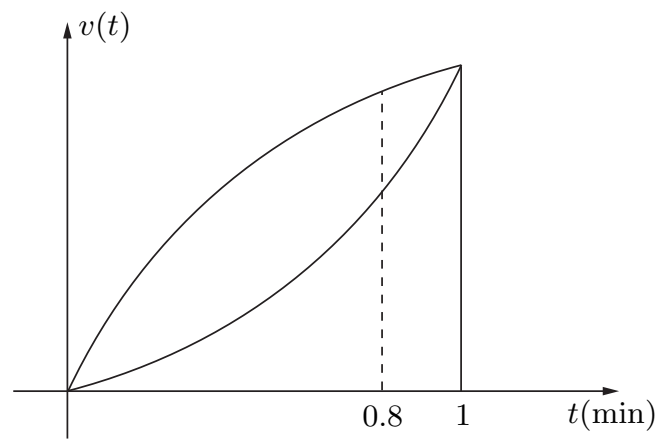

a) Velocities of cars

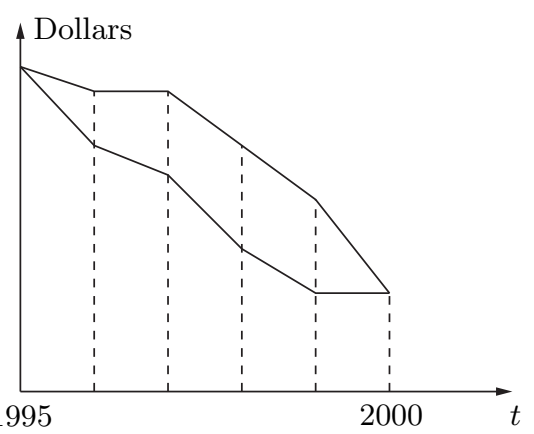

b) Deficit reduction plans

Figure 2

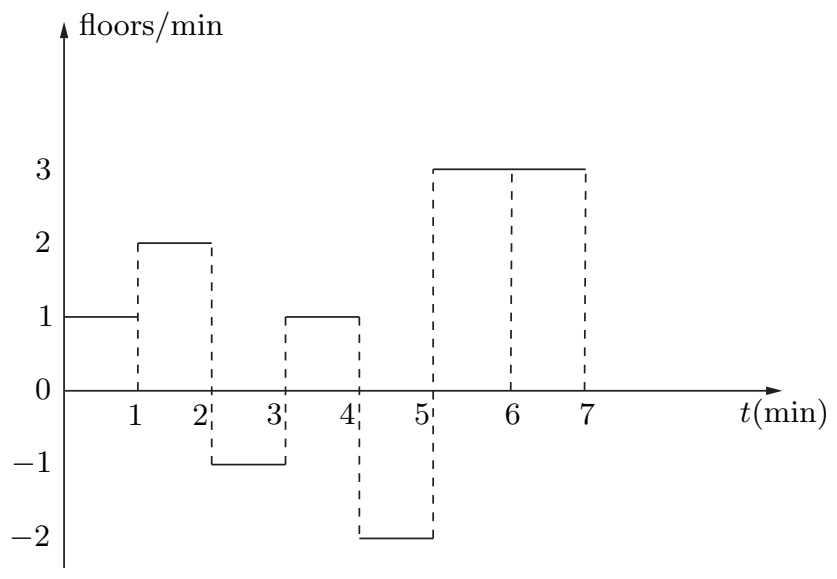

Figure 3. Velocity of an elevator

2. In Figure $2 \mathrm{~b}$ the development of the deficit (of a big company) according to two different deficit reduction plans between the years 1995 and 2000 is shown. Which one is the better plan? Why? What does better mean in this context?

3. In Figure 3 the "velocity" of an elevator is shown in a time period of 7 minutes. We see that during the first minute it has a velocity of +1 floor $/ \mathrm{min}$ and during the third minute a velocity of -1 floor $/ \mathrm{min}$. On which floor would somebody end up after using this elevator during the shown 7 minutes if he started at the ground floor and if he never left the elevator in between? 


\subsection{Examinations -}

"What you test is what you get"

Examinations play an important role in teacher training, indeed. But their aim should not be exclusively to assess the performance of students. If we want to increase the effect of teaching we have to start by reviewing and adapting all the kinds of our examinations. When doing so we should keep in mind the message of "what you test is what you get"!

Pupils and students very likely will learn subjects and matters just to pass the exam. Therefore, if we want students to prepare themselves in a special "way" we must - according to our aims - adapt both, our courses and the exams. By our experience, there are sometimes severe differences between the content and aim of a course and the content and kind of corresponding exams. Exams often do not agree with the philosophy or content of the courses. For instance, it would make only little sense to stress pre-formal reasoning, understanding, heuristics and the like during the courses and - on the other hand - to expect the students to do exclusively exercises like "compute the following integrals ..." in their exams. Also, the other way round: we can't expect our students to answer questions like "what is an integral?" in a satisfactory way, if the course on integrals is nearly exclusively concerned with some special techniques of integrating.

We should force courses and exams in which following activities are more important than in the past: pre-formal reasoning, abilities of explaining, heuristic strategies of students, simply talking about mathematics in a correct but not only formal way, describing the contents of a course with own words.

We, for example, sometimes ask students during oral exams: "What did we learn in this course?" , "What would you tell somebody else was the content of the course? Could you give some main threads of thought or fundamental ideas along which the subject of the course was developed?" These are obviously questions that you would expect to be easily answered by students having prepared well for the exam. But answers can be very disappointing, even when given by students who answer so-called "concrete" questions properly, i.e. questions like "prove Taylor's theorem!" or similar. Teacher educators also, for example, should try to ask student teachers "Why, by your believe, do we use vectors?" or similar questions. And - in many cases - you will be astonished by the answer, because you may think that such "things" had become clear automatically in your course. Many teachers think that students will find the main threads of thought by themselves, the basic and "leading" ideas between all those "concrete" theorems, proofs and examples which they have to learn in order to pass the usual kind of exams. But 
this is not the case, even it does not suffice to just shortly stress such threads of thought during the lecture (what every good lecturer will do anyway). We must stress them several times explicitly during the courses and within the exams!

\section{References}

[1] N. Balacheff et al., What is Research in Mathematics Education and What Are Its Results?, European Mathematical Society, Newsletter, no. 8 (June 1993), 14-18.

[2] T. J. Cooney, A Beginning Teacher's View of Problem Solving, Journal for Research in Mathematics Education 16 (1985), 324-336.

[3] T. J. Cooney, The Issue of Reform: What Have We Learned from Yesteryear?, Mathematics Teacher 81 (1988), 352-363.

[4] T. J. Fletcher, Is the Teacher of Mathematics a Mathematician or not?, Schriftenreihe des IDM Bielefeld 6 (1975), 203-218.

[5] T. J. Fletcher, The Mathematical Preparation of Teachers, Content and Method, Proceedings of ICME 4, (M. Zweng et al., eds.), Boston, 1983, 111-113.

[6] H. Humenberger and H.-C. Reichel, Fundamentale Ideen der Angewandten Mathematik und ihre Umsetzung im Unterricht, Bibliographisches Institut, Mannheim Wien - Zürich, 1995, (now: Spectrum, Heidelberg).

[7] D. Gale, Proof as Explanation, Mathematical Intelligencer 12 (1990), 1, 4.

[8] H.-C. Reichel, Teaching Student Teachers: Integration of Mathematics Education into "Classical" Mathematics Courses, Journal für Mathematik-Didaktik 12 (1991), 367-377.

[9] E. C. Wittmann, The Mathematical Training of Teachers from the Point of View of Education, Journal für Mathematik-Didaktik 10 (1989), 291-308.

[10] E. C. Wittmann, Mathematics Education as a "Design Science", Educational Studies in Mathematics 29 (1995), 355-374.

[11] E. C. Wittmann, Developing Mathematics Education in a systemic process, Educational Studies in Mathematics 48 (2001), 1-20.

HANS HUMENBERGER

IEEM, FB MATHEMATIK

UNIVERSITÄT DORTMUND

D-44 221 DORTMUND

GERMANY

E-mail: Hans.Humenberger@math.uni-dortmund.de

HANS-CHRISTIAN REICHEL ${ }^{\dagger}$

INSTITUT FÜR MATHEMATIK

UNIVERSITÄT WIEN

STRUDLHOFGASSE 4, A-1090 WIEN, AUSTRIA

(Received June 3, 2002) 